\title{
How Trade-off between increasing crop yield and privacy protection
}

$$
\text { Ling } L i^{1, a}
$$

\section{Solbridge International Business School,Daejeon Korea}

Keywords: Predictive Planning System ,Privacy Protection,Cloud Computing,Artificial Intelligence

Abstract:Advances in technology has improved the precision of seed,allowing farmers to use fewer loads of fertilizer and helping them saving an amount of money.But these applications of technology relies on the data from farmers.As a result,many farmers worried about these data will be misused by these service providers.Governments and some professional institutions should take actions or perfect regulations or legal terms to protect farmers’ privacy.Cloud computing can be another alternative for farmers in terms of flexibility.But it will bring about the same privacy problem.And technological methods like artificial intelligence can be applied to the practice.

\section{Introduction}

Like many other business,farming is being reshaped by information technology.Many tractors and combines today are guided by Global Positing System satellite-based navigation systems. The system issues instructions for hoses to deliver precise amounts of fertilizer right into the grooves cut by the tiller.The system helps steer the equipment,so farmers are able to monitor progress on iPads and other tablet computers in their tractor cabs.However,this system requires farmers to submit their data on their soil,field boundaries and so on.More and more farmers are worry about their privacy cannot be protected well.

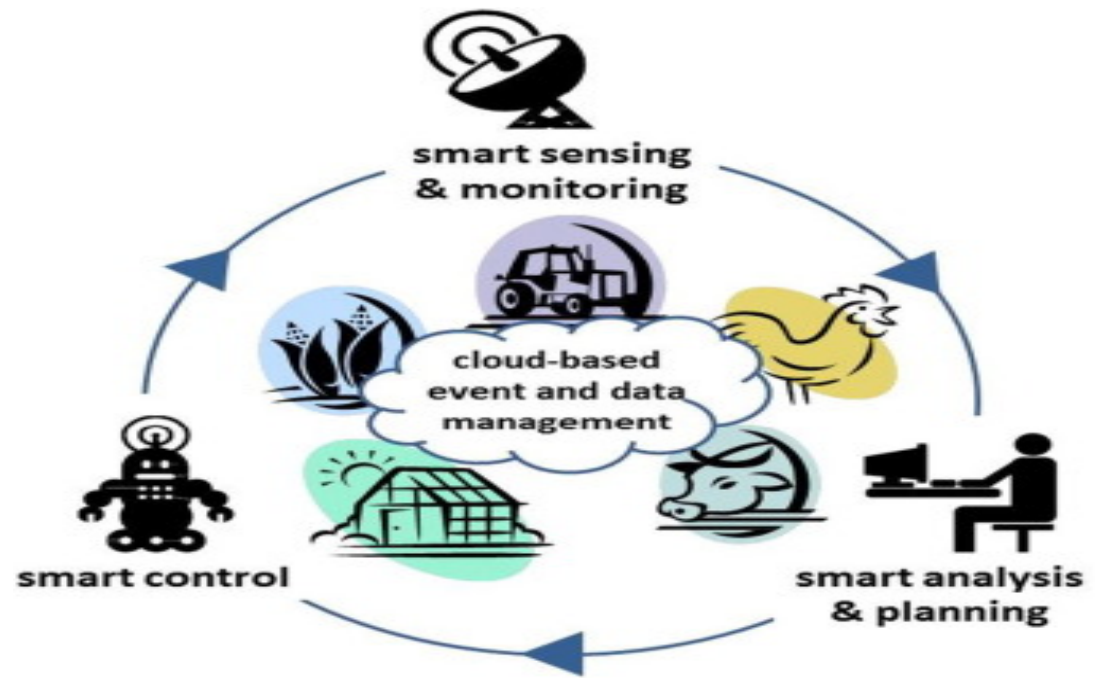

Fig. 1.

The cyber-physical management cycle of Smart Farming enhanced by cloud-based event and data management (Wolfert et al., 2014). 


\section{Predictive Planning System}

The predictive planning system can help farmers improve crop yield.Firstly,farmers can send known information ,like data on field boundaries,historic crop yields and soil conditions,to the service provider.And the service provider has owned a business intelligence infrastructure, which was based on the database. This database collect information from not only from farmers, but also suppliers,mobile services, social media ,other farmers and so on.Then the service provider can use a set of business analytic tools,including predictive analytics ,models,data mining OLAP and big data analytics to calculate the optimal solution.After that,the service provider can send recommendations to the farmer.The farmer can read these recommendations via different user interface,such as mobile phones and web portal.Then the farmer can upload recommendations into computerized planting equipment.Finally, tractors or other machines equipped with this system and GPS allow farmers in their cabs to monitor business activities.Meanwhile,these location data were recorded in the iPad or other tablet computers.And this service provider with geographic information systems,can also offer farmers weather and other information to help them manage crops better.

\section{Issues on Privacy Protection}

However,during this process,the private information like the location of equipment,historic crop yields has to be disclosed to the service providers, who are also seed sellers.And whether the recent surge in seed prices is relative with the collection of data from farmers remains unknown,even though they explained that the increase in price is the result of using genetically modified seeds.Besides,Monsanto,a big agricultural companies said that it supports industry-wide standard for managing information collected from fields.And the company aims to build a free online data storehouse where farmers could upload information ranging from crop yields to planting dates.Monsanto says it wouldn't access the data without permission from farmers.(Laudon C \&P, 2017).However,this is just statement of Monsanto.As customers,they are not clear whether Monsanto sell this information to others or misuse them.And sometimes users are required to agree on some legal documents and privacy policy,but these legal terms are too academic for common customers,they are prone to skip reading these.Besides,farmers cannot be sure that Monsanto has the ability to secure that its database cannot be attacked by hacker,spy ware and so on.

\section{Governance of Data}

So the governance of data ownership, privacy and security are key issues to be addressed in future research.( Wolferta,Gea,Verdouwa\& Bogaardta,2017).As for internal governance of data,it is better for information analysis company like Monsanto to perfect information system department.Chief security officer. chief privacy officer and chief knowledge officer can be set up to avoid being attack from external threat.Besides,some professional institutions like the Association for Computing Machinery and the Association of Information Technology Professionals can take responsibility for the partial regulation of big agricultural data analysis 
companies. What's more,governments should perfect legal system to specify who will be accountable for the disclosure of privacy information.

But at most time,some transactions are made in the black and it is hard for governments and professional institutions to make out whether the information analysis company misuse data.

\section{Cloud Computing}

Or service providers can offer cloud computing service,where platform and software as service.It has following essential characteristics:on-demand self-service,ubiquitous network access,location-independent resource pooling(Mell and Grace,2009)

On-demand self-service allows farmers can obtain computing capabilities like how much fertilizer can maximize the crop yield as needed automatically on their own.

Ubiquitous network access and location-independent resource pooling make it possible for farmers whenever,wherever to have access to standard network and Internet devices,including mobile phones.And they don't have to wait for service providers' recommendations any more and this help break the limits of time.Rapid elasticity of cloud computing can react quickly to farmers' needs and changes in environment.

However,computing has some drawbacks.Unless users make provisions for storing their data locally,the responsibility for data storage and control is in the hands of the provider.This will result in the same problem with predictive planning system.

\section{Application of Artificial Intelligence}

It may be a good choice for technology companies to develop artificial intelligence to sell robots with the function of machine learning.If so,farmers don't have to send information to service providers.They just need to enter necessary information into the robots. This robots can be thought as hybrid AI system,including many intelligence technologies.It has its own knowledge base and has the function of forward chaining and backward chaining known as expertise system.Its calculating process can involve in case-base reasoning,which can find out existing similar case to give many alternatives. Then through genetic algorithm,they can calculate the optimal solution.Actually it is similar with the case you turn on your air condition,you just need to set up the temperature and humidity then it can work as what you want.However,considering the complexity and many changing factors of farming,in the short-term,the robot is less likely to function as well as the information analysis technology companies.But this can help farmers protect their own privacy.

However, in the future,with the development technology,artificial intelligence can be perfected to solve the trade-off between privacy protection and the use of technology to improve crop yields.

\section{Conclusion}

It is necessary for governments and professional institutions to come out speific 
legal terms to protect farmer privacy.They can also chose cloud computing and for the sake of self-service and on-demand computing,they can decide how much the degree of disclosure of data on their own.In the short-term,due to limitation to technology,if farmers want high-level of seed precision,they have to trade off between customized service and privacy protection.

However,in the future,with development of artificial intelligence,they don't have offer service providers their own information to get better service.The robots,a kind of AI can calculate what kind of farming method is best for farmers.

\section{References}

[1]J. Wolfert, C.G. Sørensen, D. Goense.A Future Internet Collaboration Platform for Safe and Healthy Food from Farm to Fork, Global Conference (SRII), 2014 Annual SRII

[2]Kenneth C\&Jane P.Laudon How Much Does Data-Driven Planting Help Farmers.form Management information system.2017:529

[3]Sjaak Wolferta ,Lan Gea,Cor Verdouwa\&Marc-Jeroen Bogaardta.Big Data in Smart Farming,2017. Retrieved from:

http://www.sciencedirect.com/science/article/pii/S0308521X16303754

[4]Mell,Peter and Tim Grance."The NIST Definition of Cloud Computing"Version 15. NIST.October 17,2009 